\title{
SOSIALISASI PELAKSANAAN SP2TP MENGGUNAKAN PIECES DI PUSKESMAS LUBUK BUAYA
}

\section{Socialization of Recording and Reporting System SP2TP Implementation Using PIECES In the Center for Community Health In Lubuk Buaya}

\section{Linda Handayuni ${ }^{1 *}$ \\ Hendra Nusa Putra ${ }^{2}$}

*ISTIKES Dharma Landbouw Padang, Sumatera Barat, Indonesia

*email: lindahandayuni@gmail.com

\begin{abstract}
Abstrak
Pusat Kesehatan Masyarakat yang selanjutnya disebut Puskesmas adalah fasilitas pelayanan kesehatan yang menyelenggarakan upaya kesehatan masyarakat dan upaya perseorangan tingkat pertama, dengan lebih mengutamakan upaya promotif dan preventif. Sistim Pencatatan dan Pelaporan (SP2TP) merupakan kegiatan pencatatan dan pelaporan Puskesmas secara menyeluruh (terpadu) dengan konsep wilayah kerja puskesmas. PIECES meliputi Perfomance, Information, Economic, Control, Efficiency dan Service. Puskesmas Lubuk Buaya sudah menggunakan aplikasi e-Puskesmas dan sudah mempunyai PIECES tetapi belum sempurna dalam penerapan aplikasinya.

Tujuan dari pengabdian masyarakat ini agar pelaksanaan SP2TP dengan menggunakan PIECES lebih baik di Puskesmas Lubuk Buaya. Metode yang digunakan dengan Research Development. Hasil kinerja petugas rekam medis pada pelaksanaan epuskesmas sudah berjalan dengan baik pada information masih belum akurat dalam memberikan informasi, economy masih kurang sarana dan prasarana dalam kelancaran pelaksanaan e-puskesmas. Pada control masih terdapat kesalahan pada data sehingga pengawasan masih kurang terjamin, efficiency ditemukan belum efisiensi peningkatan kinerja puskesmas dan service masih ada proses yang belum terlaksana. Pada pelaksanaan SP2TP dengan menggunakan PECES sebaiknya lebih dioptimalkan agar tidak terjadi kesalahan dalam informasi yang ada dipuskesmas dan bidang lain yang terkait dengan pelaporan akan lebih mudah dalam pemantau termasuk pihak ekternal.
\end{abstract}

\begin{abstract}
The Community Health Center, hereinafter referred to as the Puskesmas, is a health service facility that organizes public health efforts and first-rate individual efforts, prioritizing promotive and preventive efforts. The recording and reporting system (SP2TP) is a comprehensive and integrated recording and reporting activity for Puskesmas with the concept of puskesmas working areas. PIECES include Performance, Information, Economic, Control, Efficiency and Service. Puskesmas Lubuk Buaya already uses the e-Puskesmas application and already has PIECES but it is not yet perfect in its application. The purpose of this community service is that the implementation of SP2TP by using PIECES is better at the Lubuk Buaya Health Center. The method used with Research Development. The results of the performance of medical records officers on the implementation of e-puskesmas have been running well on the information is still not accurate in providing information, the economy is still lacking of facilities and infrastructure in the smooth implementation of e-puskesmas. In the control there are still errors in the data so that supervision is still not guaranteed, efficiency has not been found to increase efficiency in the performance of health centers and services there are still processes that have not been implemented. In the implementation of SP2TP by using PECES it should be optimized so that errors do not occur in the information available at the Puskesmas and other fields related to reporting will be easier to monitor including external parties.
\end{abstract}

(C) year The Authors. Published by Institute for Research and Community Services Universitas Muhammadiyah Palangkaraya. This is Open Access article under the CC-BY-SA License (http://creativecommons.org/licenses/by-sa/4.0/). DOI: https://doi.org//0.33084/jsm.vxix.xxx.

\section{PENDAHULUAN}

Sistem Pencatatan dan Pelaporan Terpadu Puskesmas (SP2TP) merupakan kegiatan pencatatan dan pelaporan
Puskesmas secara menyeluruh (terpadu) dengan konsep wilayah kerja Puskesmas (Laura,dkk, 2019). Sistem pelaporan ini diharapkan mampu memberikan infomasi baik bagi puskesmas maupun untuk jenjang administrasi 
yang lebih tinggi guna mendukung manajemen kesehatan (Tiara,20II). Adapun formulir laporan yang digunakan untuk kegiatan SP2TP adalah laporan bulanan yang mencakup data kesakitan (LBI), data obat-obatan (LB2), Gizi, KIA, Imunisasi dan Pengamatan Penyakit Menular (LB3), serta data Kegiatan Puskesmas (LB4).

Sistem Informasi Puskesmas tersebut datanya akan diolah oleh Profesi Rekam Medis, Menurut PERMENKES RI No. 269 tahun 2008 tentang Rekam Medis menyebutkan bahwa rekam medis adalah berkas yang berisikan catatan dan dokumen tentang identitas pasien, pemeriksaan, pengobatan, tindakan, dan pelayanan lain yang telah diberikan kepada pasien. Rekam medis merupakan sumber data primer yang digunakan untuk mengolah data asuhan medis menjadi statistik kesehatan. Rekam medis mencakup berbagai data kesehatan, oleh karena itu seorang perekam medis dituntut untuk bisa mengelola data yang ada sehingga menghasilkan sebuah informasi (Kholili, 20II). Data kesehatan yang berisi berbagai informasi yang harus dikelola dengan baik agar menghasilkan informasi yang bisa digunakan untuk dasar perencanaan dan pengambilan keputusan di bidang pelayanan kesehatan. Tujuan Penyelenggaran rekam medis adalah untuk menunjang tertib administrasi dalam rangka upaya peningkatan pelayanan kesehatan (Depkes RI, 2006).

Perkembangan teknologi yang pesat saat ini telah meliputi hampir seluruh bidang kehidupan manusia, tidak terkecuali di bidang kesehatan. Harapan pasien dari sebuah pelayanan kesehatan adalah mendapatkan service yang cepat dan nyaman. Tingkat mobilitas pasien yang tinggi menuntut adanya komunikasi yang cepat antara pasien dengan institusi kesehatan, yang kemudian antara pasien dan dokter. Dalam mengelola dan menghasilkan informasi yang cepat dan tepat dibutuhkan media elektronik sebagai alat bantu. Kecanggihan teknologi bukan merupakan jaminan akan terpenuhinya informasi, melainkan sistem yang terstruktur handal dan mampu mengakomodasi semua informasi yang dibutuhkan dapat menjawab tantangan yang dihadapi.
Peranan teknologi informasi sebagai alat bantu mutlak dibutuhkan dalam beberapa proses dibidang kesehatan. Teknologi informasi merupakan kebutuhan dasar yang harus dipenuhi oleh suatu perusahaan atau organisasi untuk mempertahankan kelangsungan usahanya. Sistem informasi merupakan sarana untuk menyediakan informasi yang berguna dalam pengambilan keputusan organisasi dan menambah pengetahuan sehingga dapat mengurangi ketidak pastian bagi para pemakai informasi. Metode PIECES dapat digunakan untuk menganalisis masalah dan kelemahan dari sistem lama. PIECES sendiri meliputi Kinerja (Perfomance), Informasi (Information), Ekonomi (Economic), Kontrol (Control), Efisiensi (Efficiency), dan Pelayanan (Service) (Tullah, 2014)(Setyaningrum.A, 2015).

Puskesmas Lubuk Buaya dengan didapatkan beberapa permaslahan pada sistem informasi, salah satunya pada proses pengentrian data angka kunjungan sakit (LB I) petugas rekam medis mempunyai pekerjaan 2 kali karena setelah mengentri data tersebut didalam ePuskesmas lalu ditulis kembali ke sebuah formulir yaitu formulir pasien BPJS dan formulir pasien umum, dan di akhir pelayanan diinpiutkan lagi ke microsoft excel untuk pelaporan ke Dinas Kesehata, dimana jumlah kunjungan sakit setiap hari lebih kurang 100 orang.

Petugas rekam medis juga melakukan pengentrian data kunjungan sehat yaitu LB 4 di aplikasi primary care yang dilakukan sebanyak 3500 kunjungan sehat untuk dilaporkan kepada Dinas Kesehatan Kota Padang setiap bulan, akan tetapi laporan kunjungan sehat tersebut tidak akurat datanya karena tanggal yang dientrikan kedalam aplikasi primary care tidak sama dengan tanggal yang ada diformulir kunjungan sehat tersebut. Berdasarkan data diatas perlu dilakukan sosialisasi dalam pelaksanaan Sistem Informasi Puskesmas dengan Menggunakan Metode PIECES di Puskesmas Lubuk Buaya

\section{METODOLOGI}


Metode yang digunakan dengan Research Development menciptakan hubungan, dan mengembangkan dan menerapkan strategi yang meningkatkan daya saing kelembagaan. dan juga dilakukan wawancara kepada petugas yang melaksanakan. Sampel dalam penelitian ini adalah program yang sudah diberikan oleh dinas kesehatan dan petugas yang ada dipuskesmas. Dimana dalam pelaksanaannya peneliti langsung melatih petugas yang bertanggung jawab.

\section{HASIL DAN PEMBAHASAN}

\section{Langkah Menginput Data Pasien Ke Aplikasi e-Puskesmas}

I. Langkah pertama melakukan login ke e-Puskesmas. Seperti terlihat pada gambar sebagai berikut:

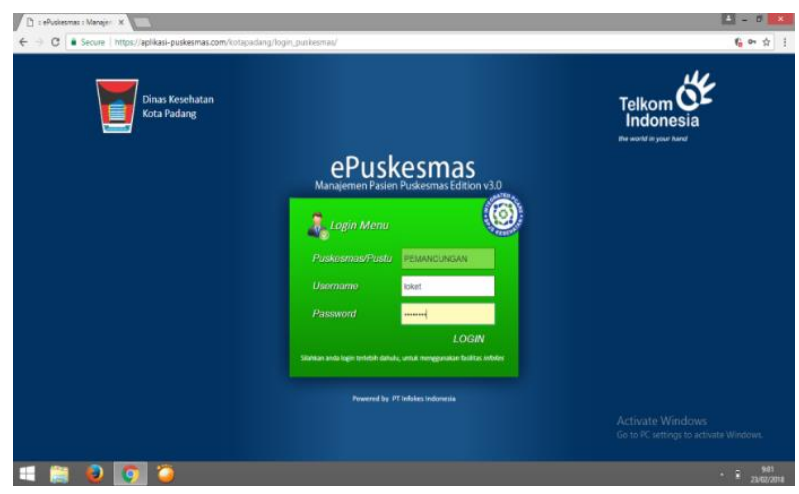

Gambar I. Login e-Puskesmas Lubuk Buaya

2. Langkah kedua, pilih menu pendaftaran, klik pendaftaran pasien. Seperti terlihat pada gambar berikut:

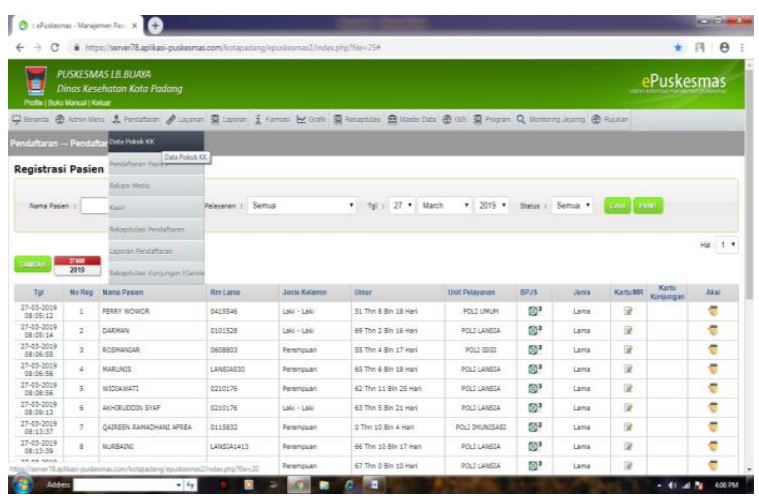

Gambar 2. Menu Pendaftaran

3. Lalu akan tampil pada layar komputer seperti pada gambar berikut:

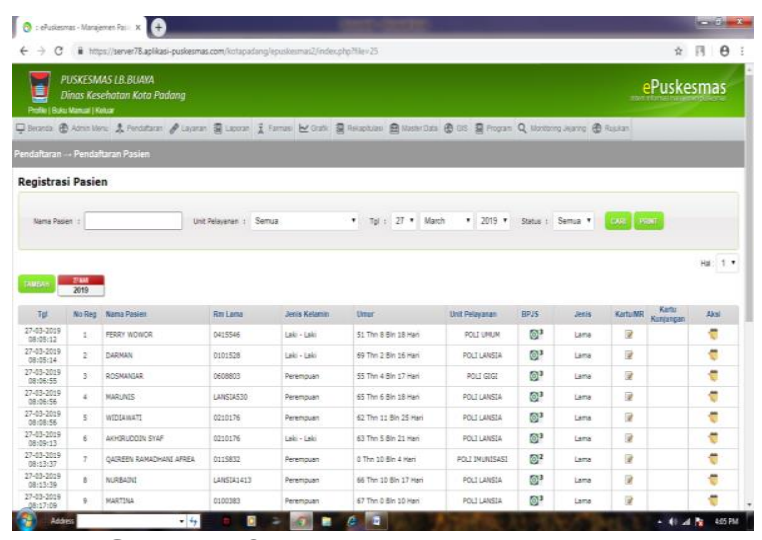

Gambar 3. Tampilan layar Registrasi pasien

4. Langkah ketiga, pada menu pendaftaran pasien klik tambah maka akan tampil pada layar komputer seperti pada gambar berikut:

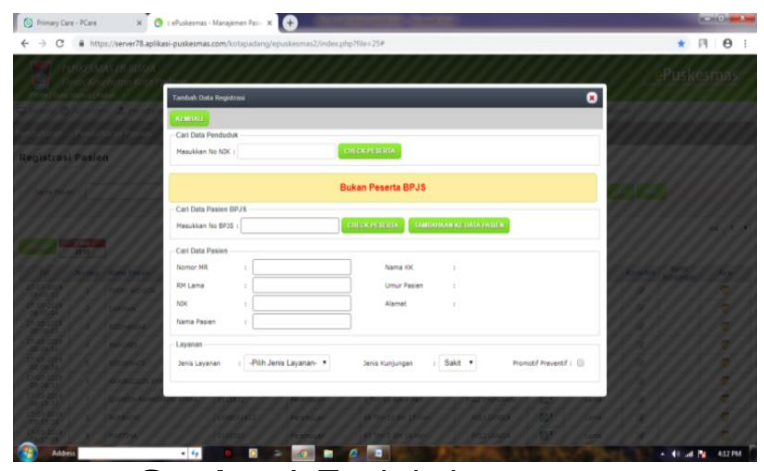

Gambar 4. Tambah data registrasi

Setelah tampil form pada gambar diatas maka petugas meng-input nomor BPJS jika pasien BPJS dan meng-input Nomor Induk Kependudukan (NIK) jika pasien umum. Apabila pasien baru maka klik menu tambahkan ke data pasien.

5. Langkah keempat, apabila penginputan nomor BPJS sudah selesai maka langkah selanjutnya yaitu melakukan pengecekan kartu BPJS apakah aktif atau tidak. Seperti terlihat pada gambar berikut: 


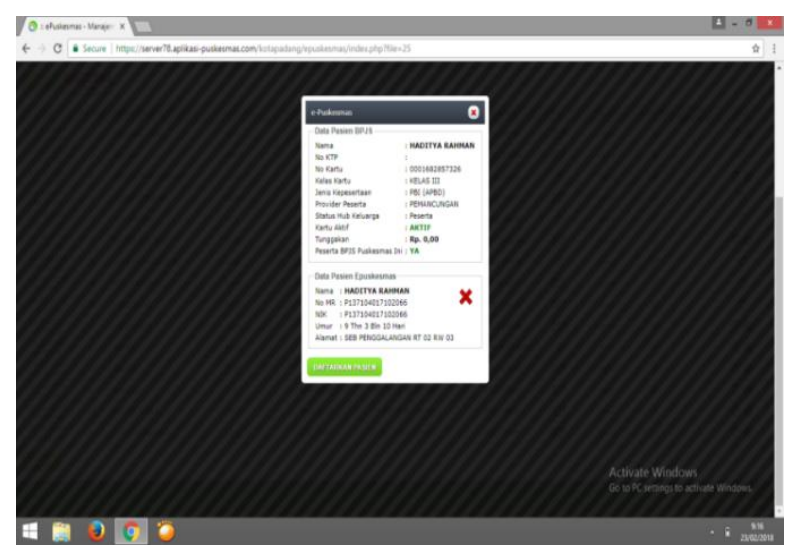

Gambar 5. Cek Kartu

Setelah kartu dicek maka pilih jenis pelayanan pasien yang bersangkutan. Seperti pada gambar berikut :

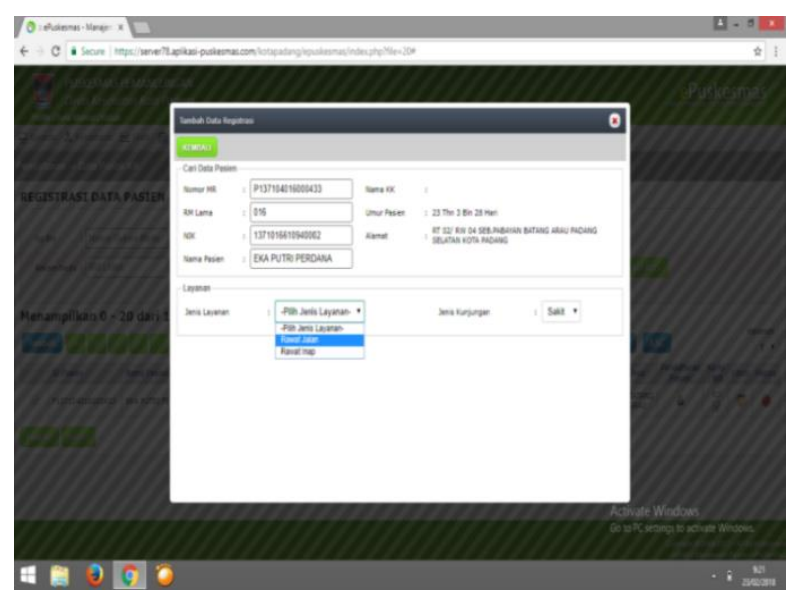

Gambar 6. Tampilan Jenis Pelayanan

6. Setelah langkah I sampai dengan 4 dilakukan, maka pasien sudah terdaftar. Seperti terlihat pada gambar dibawah ini.

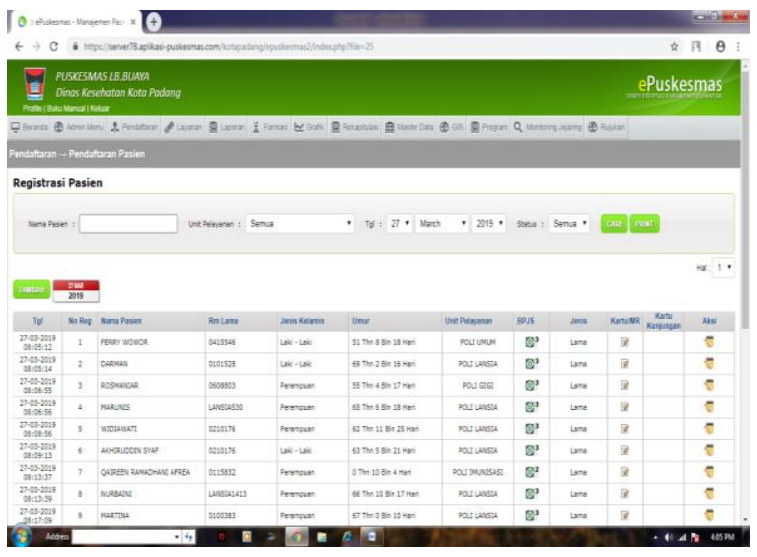

Gambar 7. Registrasi Pasien

Jika langkah-langkah diatas telah dilakukan dengan benar, maka data dan nomor rekam medis pasien telah tersimpan dengan lengkap didata pokok KK ePuskesmas Lubuk Buaya.

\section{Pelaksanan Sistem e- Puskesmas Berdasarkan Metode PIECES}

\section{Pelaksanaan e-Puskesmas Pada Kinerja (Performance)}

Performance memiliki peranan penting untuk menilai proses atau prosedur yang ada masih mungkin ditingkatkan kinerjanya dan melihat sejauh mana dan seberapa handal suatu sistem informasi dalam berproses untuk menghasilkan tujuan yang diinginkan. Hasil kinerja petugas rekam medis pada pelaksanaan e-puskesmas sudah berjalan dengan baik yang didapatkan dari hasil wawancara.

\section{Pelaksanaan e-Puskesmas Pada Informasi (Information)}

Pada Informasi e-puskesmas merupakan hal yang penting pada pihak manajemen dan user untuk melakukan prosedur selanjutnya. Informasi yang didapatkan dari aplikasi e-puskesmas masih memberikan informasi yang belum akurat dari hasil wawancara.

\section{Pelaksanaan e-Pusekesmas Pada Ekonomi} (Economy)

Pada pelaksanaan e-puskesmas dari segi ekonomi dilihat dari server di setiap puskesmas yang diciptakan dari Dinas Kesehatan Kota. Faktor dari segi pembiayaan epuskesmas masih kurang yang disebabkan kurangnya sarana dan prasarana dalam kelancaran pelaksanaan epuskesmas.

\section{Pelaksanaan e-Puskesmas Pada Pengawasan (Control)}

Pada pelaksanaan pengawasan e-puskesmas lubuk buaya padang hanya dilakukan oleh kepala ruangan rekam medis, untuk mendeteksi kesalahan atau kecurangan yang didapatkan. Dari wawancara yang dilakukan dengan kepala ruangan rekam medis masih terjadinya kesalahan pada data, sehingga pengawasan terhadap data masih kurang terjamin. 


\section{Pelaksanaan e-puskesmas Pada Pelayanan (Service)}

Pada pelayanan sistem e-puskesmas masih tergolong lama, pada observasi yang ditemukan masih ada kendala pada proses pelaksanaan e-puskesmas. Sehingga pelayanan menjadi kurang efektif dan proses pelayanan selanjutnya menjadi lama.

\section{KESIMPULAN}

Pada pelaksanaan SP2TP dengan menggunakan PECES sebaiknya lebih dioptimalkan agar tidak terjadi kesalahan dalam informasi yang ada dipuskesmas dan bidang lain yang terkait dengan pelaporan akan lebih mudah dalam pemantau termasuk pihak ekternal.

\section{UCAPAN TERIMA KASIH}

Dalam penyusunan naskah publikasi ilmiah yang sederhana ini, peneliti mendapat bantuan dari berbagai pihak, untuk itu peneliti mengucapkan terima kasih kepada seluruh sivitas akademika yang telah membantu dalam proses penelitian, enumerator penelitian yang meluangkan waktu dalam pengumpulan data, dan instansi pelayanan kesehatan sebagai tempat penelitian yang telah memberikan kesempatan. Akhirnya ucapan terima kasih disampaikan kepada semua pihak yang tidak dapat disebutkan satu persatu

\section{REFERENSI}

I. Laura., Firdawati., Edison. Analisis Pelaksanaan Sistem Pencatatan dan pelaporan Terpadu Puskesmas (SP2TP) di Kota Padang Tahun 2018. Jurnal Kesehatan Andalas. http://jurnal.fk.unand.ac.id. 2019.

2. Menkes RI. Peraturan Menteri Kesehatan Republik Indonesia Nomor: 269/Menkes/Per/lii/2008 Tentang Rekam Medis, Jakarta, 2008.

3. Menkes RI. Peraturan Menteri Kesehatan Republik Indonesia Nomor: 75 Tahun 2014 Tentang Pusat Kesehatan Masyarakat, Jakarta,20I4.
4. Menkes RI. Peraturan Menteri Kesehatan Republik Indonesia Nomor: 55 Tahun 2013 Tentang Penyelenggaraan Pekerjaan Rekam Medis, Jakarta, 2013.

5. Kholili, Ulil. Pengenalan Ilmu Rekam Medis pada Masyarakat serta Kewajiban Tenaga Kesehatan di Rumah Sakit. Jurnal Kesehatan Komunitas, Vol. I, No.2. Mei 201 I.

6. Setyaningrum, Arma. Analisis Sistem Informasi Registrasi Pasien dengan Metode PIECES di Rumah Sakit Mulia Hati Wonogiri. Program Studi Kesehatan Masyarakat Universitas Muhammadiyah Surakarta. 2015.

7. Adiguna, Arel Riedsa. Analisis Dan Perancangan Sistem Informasi Manajemen Gudang Pada Pt Mitra Pinasthika Mulia Suarabaya. Jurnal Pengembangan Teknologi Informasi Dan Ilmu Komputer. Vol.2 No. 22018.

8. Handayuni, Linda "Analisis Pelaksanaan Sistim Pencatatan dan Pelaporan Terpadu Puskesmas di Puskesmas Nanggalo" In Jurnal Manajemen Informasi Kesehatanlndonesia (JMIKI), Vol 7,pp.I5I, Oktober 2019.

9. Handayuni, Linda “Analisis Pelaksanaan Pengelolaan Rekam Medis di Puskesmas Muara Madrasah Kecamatan Jangkal Provinsi Jambi" In Administration \& Health Information Of Journal" Padang, Vo.I, pp I-9, Februari 2020.

10. Suryani, N,D., Solikhah. Sistem Pencatatan dan Pelaporan Terpadu Puskesmas (SP2TP) di Wilayah Dinas Kesehatan Kabupaten Dompu Provinsi NTB. Fakultas Kesehatan Masyarakat, Universitas Ahmad Dahlan Yogyakarta. Kesmas Vol. 7 No. I. ISSN: 1978-0575. Maret 2013.

II. Tullah, Rahmat. Evaluasi Penerapan Sistem Informasi Pada Politeknik Lp3i Jakarta.Dengan Metode Pieces.Jurnal Sistofek Global.Vol.4 No. I. 2014 